
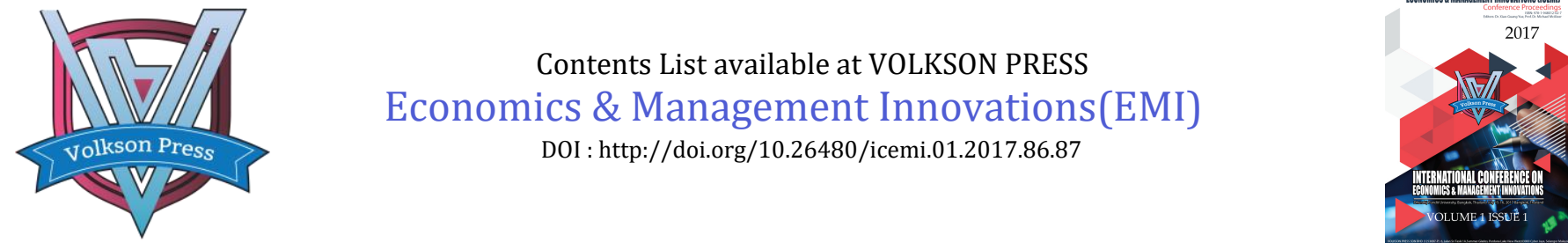

\title{
The Agglomeration of Cultural Tourism Industry in Hubei Province and the Research of its Competitiveness
}

\section{Long Minghui}

Wuhan Donghu University, Wuhan, Hubei, China

642604051@QQ.COM

This is an open access article distributed under the Creative Commons Attribution License, which permits unrestricted use, distribution, and reproduction in any medium, provided the original work is properly cited.

\section{ARTICLE DETAILS}

\section{Article History:}

Received 02 october 2017 Accepted 06 october 2017 Available online 11 october 2017

\section{Keywords:}

Hubei province, cultural tourism industry, agglomeration

\section{ABSTRACT}

Cultural tourism industry is one of the important components of tourism industry, which is developed from the cultural tourism resources. It is one part of the tourism industry to meet people's consumption demand of cultural tourism. Industrial agglomeration is a particular phenomenon and effective organization form of regional economic development, and it plays an important role in economic growth. At present, Hubei province is facing the urgent demand of industrial structural adjustment and urban economic transformation. This paper aims at the development status of cultural tourism industry in Hubei province and analyzes the influence factors and existing problems of agglomeration of cultural tourism industry in Hubei province with the application of industrial agglomeration theory. In the end, it puts forward the countermeasures and suggestions to enhance the competitiveness of cultural tourism industry in Hubei province and realize sustainable development.

\section{Introduction}

The development of industrial agglomeration is the inevitable choice for the development of cultural tourism industry and the result of tourism transformation and upgrading under the new normal. In 2009, the State Council passed The Revitalization Plan of Cultural Industry, which treats the vigorous development of cultural industry as national strategy. As the tertiary industry, tourism has gradually became the pillar industry of economic development in various regions. The cultural tourism industry is an important part of modern tourism and one branch of cultural industry. The domino economic effect brought by the agglomeration of cultural tourism industry also becomes an inevitable research object. Industrial agglomeration means the process of highly centralization of one industry in some particular geographical area and industrial capital factors in the scope of space. The process of industrial agglomeration is an inevitable process of spatial development of tourism economy. Industrial agglomeration can help to increase the productivity, promote the division of labor, strengthen enterprise competitiveness and improve the infrastructure. The concept of tourism industrial agglomeration put forward in related overseas researches is defined from the optimization of industry chain and the enhancement of competitive edge based on Michael Potter's industrial agglomeration theory. McIntosh (1977) firstly proposed the concept of cultural tourism that he thought "cultural tourism includes all aspects of tourism". The motivation essentially from culture brings the activity of human. Richards (1996) thought that motivation is an important factor and cultural tourism comes from the interests in geographic and historical heritage of tourism or communities or lifestyle etc. Silberberg (1995) thought that motivations can be divided into sudden ones, subordinate ones, partial ones and strong ones in terms of its degree.

2. The Conditions for the Development of Cultural Tourism Industrial Agglomeration in Hubei Province

2.1 The abundant cultural tourism in Hubei province provides a primary condition for the development of tourism industrial agglomeration

Hubei province is a big cultural province with abundant cultural resources and rich cultural deposits where the cultural development enjoys exceptionally good conditions. To realize great-leap-forward development of Hubei, the great-leap-forward development of culture cannot be ignored. The transformation from culturally major province to culturally strong province is a major measure to strive for the construction of strategic support for the rise of central China in Hubei. Since $12^{\text {thFive-Year }}$ Plan, the tourism industry of Hubei province has gained healthy, constant and rapid development as well as prominent achievements, which lay a firm foundation for the development of tourism industry in $13^{\text {th }}$ Five-Year Plan. The cultural tourism industry is a sun-rising industry, and it plays an important role in structural adjustment, domestic demand expansion, employment increase and development promotion, etc. In recent years, Hubei province pays much attention to the development of cultural tourism industry, forming the new situation of cultural tourism industry with participation of various economic compositions and development in various forms. Jing-Chu Culture has distinctive regional characteristic sand it is an important part of Chinese national culture. It has learnt a lot from characteristics of Shang and Zhou Culture. It has long history and it is broad and profound with distinctive regional characteristics and enormous economic and cultural development value.

2.2 The continuous expansion of the scale of cultural tourism industry provides a necessary condition for the development of cultural tourism industrial agglomeration

Tourism industry is an industry of strong relevance. The industries that are related to tourism are mainly those upstream industries and auxiliary industries that provide tourism with raw materials, components and parts, etc., and they also include those industries that are connected with or complementary to tourism for the share of some technology, marketing channels or services, such as catering industry, accommodation industry, retailing industry, entertainment industry and so on. All kinds of relevant and auxiliary industries are able to provide supports of information, technology, human resources etc., and play a dominant role in the tourism industry, so as to form an advantaged industry group.

2.3 The high attention of government provides assurance condition for the development of cultural industrial agglomeration in Hubei province

The government's policy support is the assurance condition and the "activator" for the development of cultural tourism industrial agglomeration. In the new round of develop-the-west strategy, the country has clearly pointed out the role of cultural tourism industry plays in the economic development of western China and also emphasized that every province should explore its own sustainable development road for cultural tourism according to the actual situations. Hubei Provincial Government 
pay high attention to the development of tourism. The planning, exploitation, coordination and organization of tourism resources in whole province are developed in an orderly manner.

3. The Urgent Problems that need to be Solved for the Cultural Industrial Agglomeration in Hubei

\subsection{The integration and comprehensive exploitation of cultural} resources is insufficient

The scale of present cultural tourism industry in Hubei is generally small. The economic effect of cultural tourism industry is not obvious. These phenomena are directly related to the insufficient integration and decentralized management of cultural tourism industry. The current cultural tourism resources are distributed to and managed by several departments like cultural relics, tourism, garden, religion and so on. The communication and coordination between departments are insufficient, which is harmful to the comprehensive exploitation of cultural resources.

\subsection{Single channel for investment and financing}

For a long time, the development of cultural tourism depends on the investment of government. Now with the development of the current situation, this kind of single system cannot adapt to the rapid development of cultural tourism industry. Besides, among most cultural enterprises, private or individual enterprises have small quantity and scale. Foreignfunded or joint venture enterprises are even rare. The channel of investment and financing is too single and the funds are in shortage, which has seriously restricted the development of cultural tourism industry in Hubei province.

\subsection{The management system is not suitable to the market economy}

Cultural tourism industry is influenced by many factors, resulting to inadequate revolution, lack of vigor and competitiveness as well as interior motivation for development. Therefore, it has not stepped into the track of sound development and it has a long way to go to meet the requirements of market economic system.

\subsection{Lack of management personnel in cultural tourism industry}

The training for cultural tourism industry is delayed. All regions are generally in short of qualified personnel in cultural tourism industry who are good at operation and management. The qualified personnel in cultural tourism market development are also in short.

4. Counter measures and Suggestions for Cultural Tourism Industrial Agglomeration in Hubei Province

\subsection{Highlight the characteristics of resources and cultivate competitive brands}

The cultural tourism industry is a sun-rising industry, which is the result of high utilization of cultural resources. The cultural tourism industry must develop in the mode of agglomeration. Hubei should rely on the ageold Jing-Chu culture in Hubei, create contemporary cultural tourism products and realize the agglomeration development of tourist projects with the help of major cultural themes. Hubei should also accelerate the construction of comprehensive cultural tourism scenic spots with significant influence which is based on commercial facilities and integrates cultural exhibition, cultural experience, modern commerce, leisure entertainment and leisure sightseeing, etc.

\subsection{Strengthen the project carrier and promote investment}

To enhance the development of cultural tourism industry, it is needed to promote investment vigorously according to the thought of development of cultural tourism industry and take project as carrier. Adopt the method of market selection and government promotion, enlarge the attraction of foreign investment, combine and regroup cultural tourism industries and also use the method of capital operation through formulating and implementing scientific planning, improvement of infrastructure construction, government subsidy and building service platform. Integrate the factors of production and management with collecting the strength of science and technology, it tends to be professional, scale and intensity. Dig out the regional resource advantage and build competitive brand, adopt domestic and foreign investment capital, promote the formation of cultural tourism industrial agglomeration area in Hubei and the optimization and upgrading of industry institution.

\subsection{Establish a sound management system and enlarge the} financial support

The management of tourism resources involves a lot of departments. The management system and operating system are complicated. So during the process of further development and improvement of market, it is needed to integrate the resources and sort the ownership, administration authority and management right, making the management direct and effective. The government should give more policy supports to the land, taxation and credit of tourism industry and provide multi-channe financial support. For example, set up the development fund of tourism to make up the shortage of fund budget by means of subsidy, interest subsidy and reward etc.

\subsection{Strength the cultivation of talented personnel and the} construction of talent team

Relying on the talent resources from high colleges in Hubei, establish mutual benefit and win-win cooperation between schools and enterprises develop the talent sharing system to make the education of colleges integrated into the development of tourism industry, set up and exert course reform according to the development and change of tourism industry. Set up the practice base to let students expand their knowledge in practice, and promote the development of students' professional accomplishment and professional skills.

\section{Acknowledgement}

This research was financially supported by the Humanities and social science research project of Hubei Provincial Department of Education.( [2017] No.3 Document, 17G080) One of the research results of Humanities and social science research project of Hubei Provincial Department of Education "The Agglomeration of Cultural Tourism Industry in Hubei Province and the Research of its Competitiveness".

\section{References}

[1]Julie Flowers, Katherine Eaesterling.Growing South Carolina's Tourism Cluster [J].Business and Economic Review,2006:199-213.

[2]Michael E Porter. Clusters and the new economics of competition [J]. Harvard Business Review.1998,76(6)77-90.

[3]R L Mill,A M Morrison. The Tourism System:An introduction Text[M].Prince Hall Englewood Cliffs,NJ,1985.

[4]Nulty PM.Quality standard and training needs inruraltourism [M].UNWTO,2004.

[5]Julie Jackson,Peter Murphy.Cluster in regional tourism an Austrialian case[J].Annals of Tourism Research,2006(4):1018-1035.

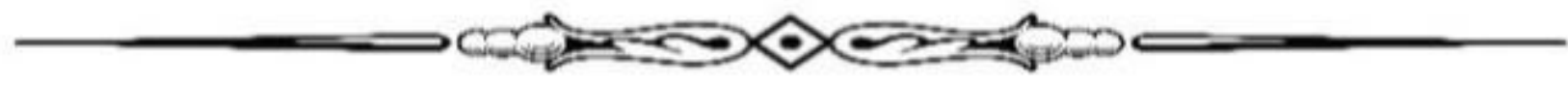

